\title{
Mechanical, Curing Parameters and Water Absorption of Hybrid Date Palm Leaf-Orange Peel Fibers Reinforced Unsaturated Polyester Composites
}

\author{
Hamza Chelali $^{1 *}$, Ahmed Meghezzi $^{1}$, Abir Berkouk $^{1}$, Mohamed Toufik Soltani $^{2}$, George Winning $^{3}$ \\ ${ }^{1}$ Laboratory of applied chemistry LCA, University of Biskra, Biskra 07000, Algeria \\ ${ }^{2}$ Laboratory of Physics of Photonics and Multifunctional Nanomaterials, University of Biskra, Biskra 07000, Algeria \\ ${ }^{3}$ Laboratory of Clariant. Howe Moss Avenue, Kirkhill Industrial Estate, Dyce, Aberdeen AB21 0GP, Scotland, United Kingdom \\ Corresponding Author Email: Hamza.chelali@univ-biskra.dz
}

https://doi.org/10.18280/rcma.310304

Received: 12 April 2021

Accepted: 11 June 2021

\section{Keywords:}

unsaturated polyester, date palm leaf fiber, orange peel fiber, hybrid composites, physical properties, curing parameters

\begin{abstract}
In this study, polymer-hybrid natural fibers composites were prepared using unsaturated polyester resin (UPR) as the matrix and a filler using date palm leaf fiber (DPLF) and orange peel fiber (OPF). The effect of DPLF and OPF on mechanical behavior (tensile strength and elongation at break), moisture absorption, UPR gel time (tgel) and peak exothermic temperature (Tpeak) were determined. The composites of UPR reinforced with DPLF and OPF were processed by hand lay-up technique. The UPR weight fraction was maintained at $90 \%$, and DPLF/OPF proportions varied so that the percentage of natural fiber was $10 \mathrm{wt} \%$. Seven (07) composites were prepared (C1, C2, C3, C4, C5, C6 and C7) with different DPLF:OPF ratios (0:0, 1:0, 0.75:0.25, 0.5:0.5, 0.33:0.67, $0.25: 0.75,0: 1)$ respectively in order to screen the possible interactions. DPLF were surface modified using 6\% Alkali treatment, OPF were used without surface modification. Unlike DPLF, OPF showed considerable increase of UPR tgel and Tpeak which act as natural inhibitor. Tensile strength and fracture strength were also impacted negatively and positively depending on the different fiber proportions. Absorption tests showed a decrease in the composites hydrophobicity which increases significantly with higher DPLF proportions.
\end{abstract}

\section{INTRODUCTION}

Because of recent concerns about the environmental issues, there has been an increased focus in research on the use of natural fibers for use in polymer reinforcement, mainly that some lignocellulosic fibers showed comparable proprieties over the synthetic fibers $[1,2]$.

Unsaturated polyester resins (UPRs) are widely used in different domains such as aerospace, electronic instrument, automobile, construction of buildings, UPRs are an important part of thermosetting polymers and widely used due to high chemical resistance, resistance to corrosion, low cost and ease of handling and processing [3].

World total produced orange fruit was around 48.8 million tons per year in 2015 , and it has been estimated that more than a half weight of an orange fruit ends as waste, a waste that represents 15 to 25 million tons per year. With $80 \%$ of total produced orange being used for industrial purposes (such as extracts, juices...) the amount of waste produced is large and the use of the orange peel fibers (OPF) for other products is worthwhile to reduce waste [4].

Date palm leaf fiber (DPLF) represents a large waste stream in Algerian Sahara, worldwide the issue is worse with hundreds of thousand tons of date palm leaves estimated. As date palm leaves have an important mechanical strength they have been widely studied in polymer reinforcing and therefore offer a use for this waste product [5].

Polypropylene matrix reinforced by hybrid Banana and Coir fibers was studied before by Gunturu et al. [6] where it was concluded that fiber hybridization has a significant effect on the mechanical and thermal properties as well as on the microstructure. It was reported in this study that change in the composite properties was directly related to fiber orientation and length and mainly dependent on the banana fiber than the coir fiber.

Alkali treated date palm leaf fiber (DPLF) and dune sand hybrid unsaturated polyester composites have been studied before by Meftah et al. [7] thermogravimetric analysis indicated that $6 \%$ alkali treated DPLF gives improved thermal stability, while SEM showed better interfacial interaction. Moreover, the water uptake tests indicated that the surface modified DPLF increases hydrophobicity over non treated DPLF.

Epoxy matrix reinforced by hybrid hemp and palmyra fibers was studied by Lakshmi Narayana et al. [8] with a focus on the effect of the stacking sequence of the fibers, where it has been noticed that incorporation of hybrid fibers increases the structural void and water uptake, with an important increase in both tensile and flexural strengths also seen.

Abdullah et al. [9] studied the UV radiation effect on Jute/Sisal unsaturated polyester hybrid composites, the results showed that a Jute-Sisal ratio of 1-3 improved tensile strength by $125 \%$ compared to neat UPR, and bending strength improvement by $162 \%$ and a $235 \%$ increase in the bending modulus.

Dahad et al. [10] studied the effect of adding OPF and date 
seeds (DSF) on the unsaturated polyester resin (UPR) and compare the results to composites with silica and carbon. The results indicated that OPF has an effect of $5 \%$ on thermal conductivity of composites, while it was noticed that the maximum flexural strength improved by $153.4 \%$ when OPF is added at a $5 \mathrm{wt} \%$ ratio.

Adhikari and Gowda [11] studied short and random oriented Banana/Jute hybrid polyester composites, and it was found that the impact strength of prepared composites increases with increase in fiber loading up to $25 \mathrm{wt} \%$, however the optimum fiber volume fraction for tensile and flexural strengths was found to be $15 \mathrm{wt} \%$.

The work presented in this article focuses on the synthesis of a hybrid UPR composites using two (02) different natural fibers with aim of UPR improvement in terms of mechanical properties and investigation of water uptake, but also for the use of these natural fibers since they are considered as waste. OPF and DPLF were chosen due to their availability mainly DPLF which is abundant in the Sahara. The effect of both fillers on the tgel and Tpeak was studied followed by determination of tensile strength and fracture strength as well as water uptake.

\section{MATERIALS AND METHODS}

\subsection{Materials}

The unsaturated polyester resin (UPR) used in this study is an Orthophthalic UPR with a commercial name PRE-36 supplied by POLRES POLYESTER, Turkey. The initiator was purchased from AkzoNobel under trade name BUTANOX-50, which is a general purpose methyl ethyl ketone peroxide (MEKP)

The DPLF (Phoenix dactylifera L.) used in this study was collected from Biskra State in Algeria, Table 1 shows the chemical composition of DPLF:

Table 1. Chemical composition of DPLF [12]

\begin{tabular}{cc}
\hline Total extractives & $32.86 \%$ \\
\hline Cellulose & $47.14 \%$ \\
Hemicellulose & $16.13 \%$ \\
Lignin & $36.73 \%$ \\
\hline
\end{tabular}

After thorough washing using raw water and then using distilled water, DPLs were cut to small pieces of 2-5 cm long and immersed into a $6 \% \mathrm{NaOH}$ bath for 24 hours at $40^{\circ} \mathrm{C}$, at the end of the mercerization, the DPLF was neutralized using acetic acid and rinsed using distilled water. The DPLF was then dried at $80^{\circ} \mathrm{C}$ for 24 hours and was ground using a home grinder until a fine DPLF particles were obtained.

OPF was obtained from the peels of the orange fruits harvested from orange trees (Citrus sinensis) from Blida state, Algeria. The Table 2 shows the chemical composition of the orange peels fiber where it can be noticed the low content of ash:

Orange peel is also rich in phenolic compounds, Table 3 below summarizes some of them:

Table 2. Chemical composition of OPF [13]

\begin{tabular}{cc}
\hline Cellulose & $13.61 \%$ \\
\hline Hemicellulose & $6.10 \%$ \\
Lignin & $2.10 \%$ \\
Ash & $1.50 \%$ \\
\hline
\end{tabular}

Table 3. Phenolic compounds in Maltease OPF [14]

\begin{tabular}{ccc}
\hline Phenolic compound & $\mathbf{g} / \mathbf{1 0 0 g}$ & \% of total phenols \\
\hline Neohesperidin & 1.312 & 48.88 \\
Hesperidin & 0.990 & 36.87 \\
Nobiletin & 0.109 & 4.06 \\
Eriocitrin & 0.061 & 2.27 \\
Naringin & 0.060 & 2.23 \\
Narirutin & 0.031 & 1.15 \\
\hline
\end{tabular}

The orange peels were rinsed using distilled water and dried in $70^{\circ} \mathrm{C}$ for 72 hours. The orange peels were then ground to a fine powder.

\subsection{Preparation of UPR/DPLF-OPF composites}

A $20 \mathrm{~cm} \times 20 \mathrm{~cm} \times 4 \mathrm{~mm}$ aluminum mold was used for hand lay-up composites preparation. Prior to placing in the mold, the required UPR is poured into a glass vessel and then the required DPLF/OPF weights added so that the UPR represents $90 \%$ by weight. Then, $1 \%$ MEKP is added and the mixture is well stirred for 2 minutes and then poured into the mold.

\subsection{Characterization}

2.3.1 Measure of gel time and peak exothermic temperature

The determination of gel time (tgel) and peak exothermic temperature (Tpeak) were conducted as defined in ASTM D2471, with taking into account all necessary safety considerations.

\subsubsection{Mechanical tests}

Tensile strength and elongation at break of the prepared composites were determined in accordance with ASTM D638 using a ZwickRoell Z50 tensile test machine at ENICAB company level, Biskra, Algeria.

\subsubsection{Morphological analysis}

The microstructure of the prepared composites was studied using Quanta 250 Scanning Electron Microscope (SEM) from FEI.

\subsubsection{Thermal analysis}

For thermal proprieties determination, LABSYS evo instrument was used from SETARAM, which is a TGA/DSC combined instrument. Temperature range was from $25^{\circ} \mathrm{C}$ to $500^{\circ} \mathrm{C}$ with a heating increment of $10^{\circ} \mathrm{C} / \mathrm{min}$.

\subsubsection{Moisture absorption}

The Relative rate of water absorption of the prepared composites were determined by immersing a $1 \mathrm{~cm} \times 1 \mathrm{~cm}$ samples in distilled water at constant temperature $\left(25^{\circ} \mathrm{C}\right)$ for 40 days and by weighting the samples every 6 hours in the first week, then, every 24 hours for the remaining time. Prior to the test, all samples were first immersed in distilled water for ten (10) days, and then dried at $70^{\circ} \mathrm{C}$ for 24 hours. The water uptake test started by weighting the samples to the nearest $0.0001 \mathrm{~g}$. most of water uptake considerations were inspired from ASTM D570.

Percentage increase in weight was calculated to the nearest $0.01 \%$ as follows:

$$
\text { Increase in weight, } \%=\frac{\text { Wet } \text { Weight-Initial weight }}{\text { Initial weight }} \times 100
$$




\section{RESULTS AND DISCUSSION}

\subsection{Curing properties}

The measured tgel and Tpeak properties are shown the Table 4 and compared to UPR without fiber.

Table 4. Curing parameters

\begin{tabular}{cccccc}
\hline & $\begin{array}{c}\text { tgel } \\
(\mathrm{min})\end{array}$ & $\begin{array}{c}\text { Gel } \\
\text { temp } \\
\left({ }^{\circ} \mathrm{C}\right)\end{array}$ & $\begin{array}{c}\text { Peak } \\
\text { time } \\
(\mathrm{min})\end{array}$ & $\begin{array}{c}\text { Peak } \\
\text { temp } \\
\left({ }^{\circ} \mathrm{C}\right)\end{array}$ & $\begin{array}{c}\text { Gel to } \\
\text { peak } \\
(\mathrm{min})\end{array}$ \\
\hline $\begin{array}{c}\text { UPR } \\
\begin{array}{c}\text { UPR:OPF } \\
\text { (9:1) }\end{array}\end{array}$ & 10 & 32 & 21 & 98 & 11 \\
$\begin{array}{c}\text { UPR:DPLF } \\
(\text { 9:1) }\end{array}$ & 11 & 29 & 64.5 & 96 & 27.5 \\
\hline
\end{tabular}

With $10 \%$ OPF, peak exothermic temperature was slightly reduced from $98^{\circ} \mathrm{C}$ to $96^{\circ} \mathrm{C}$, however, it took $64.5 \mathrm{~min}$ to reach Tpeak with $10 \%$ OPF compared to 21 min with neat UPR which represents $307 \%$ increase in time required to reach peak temperature. Also, a delayed gelation was noticed from $10 \mathrm{~min}$ with neat UPR to 37 min with $10 \%$ OPF reinforced UPR. From the other side, the results indicated that adding $10 \mathrm{wt} \%$ DPLF to UPR has no significant effect on the curing parameters of UPR, however, $10 \mathrm{wt} \%$ of OPF caused an increase of tgel from $10 \mathrm{~min}$ to $37 \mathrm{~min}$, without significant effect on gelation temperature. Time required for the UPR to reach the peak exothermic temperature is three times (x3) more than UPR without OPF, Peak exothermic temperature (Tpeak) increased from $98^{\circ} \mathrm{C}$ to $116^{\circ} \mathrm{C}$ which is an $18 \%$ increase [15]

The inhibitory effect after adding untreated OPF is probably due to phenolic compounds in the orange peels liberating hydrogen atoms, and then reacting with free radicals from MEKP. The decrease of curing time and peak exothermic temperature will allow for unsaturated polyester resin to cure with a minimum stress and leads to a better homogenization of the resin, this contributes also to good fiber wetting as well as for void minimization by eliminating the bubbles from the resin before the end of the curing process [16].

\subsection{Mechanical properties}

The tensile strength and elongation at break properties of all prepared composites are shown in the Figure 1 below.

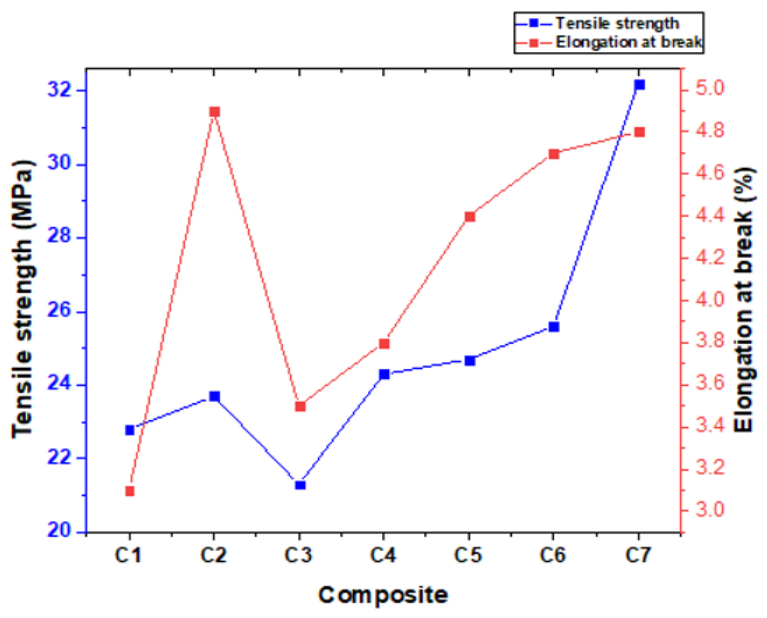

Figure 1. Composites tensile strength and elongation at break
From the Figure 1, it can be noticed that after adding $10 \mathrm{wt} \%$ DPLF in C2, an increase in tensile strength is noticed (3.94\% increase), the increase after adding $10 \%$ DPLF is in agreement with Meftah et al. [7], a 58\% improvement has been noticed also in elongation at break of $\mathrm{C} 2$.

Once OPF incorporated in $\mathrm{C} 3$, both tensile strength and elongation at break decreased significantly, but gradually with decreasing the DPLF content and increasing OPF, a continuous increase of tensile strength and elongation at break was noticed until they reached respectively $32.2 \mathrm{MPa}$ and $4.8 \%$ in $\mathrm{C} 7$.

It can be noticed that high OPF/low DPLF proportions of hybrid fillers gave better results than high DPLF/low OPF contents. Also, starting from C4 to C6, hybrid fillers showed better mechanical properties than with $\mathrm{C} 1$ (composite filled with $10 \%$ DPLF only).

Optimum tensile strength was $32.2 \pm 1.9 \mathrm{MPa}$ obtained with C7 containing $10 \mathrm{wt} \%$ of OPF and 0\% DPLF, making $41.2 \%$ improvement in tensile strength compared to non-reinforced UPR.

\subsection{Morphological properties}

Figure 4 and Figure 5 show the micrographs of fractured specimens, respectively, of C1 (10\% DPLF) and C7 (10\% OPF) where the natural fibers are randomly distributed in the matrix.

As in Figure 4, it is seen in C1 (UPR-DPLF) some DPLF de-bonding, and the fiber easily noticeable pull out. While in Figure 5, a good interfacial bonding between UPR-OPF can be observed. The micrographs show also a rough surface of OPF, while the surface is much smoother in treated DPLF, hence, the DPLF pull-out in fractured specimens is due to poor interfacial bonding that can be explained by the surface smoothness, compared to OPF in Figure 5, where the surface is rougher and almost no de-bonding.

From the other side, the matrix surface in $\mathrm{C} 1$ shows a smooth UPR surface if compared to the surface of UPR in C7 which is much rougher. It is known that the rougher surfaces give a better adhesion due to good interfacial bonding, while the smoother the surface is, the easier the fiber pull-out.

The SEM micrographs shows a morphological details that are in accordance with both tensile strengths and water uptake rates of the prepared composites.

\subsection{Thermogravimetric analysis (TGA)}

Table 5. Thermal properties

\begin{tabular}{ccccc}
\hline & C1 & C2 & C4 & C7 \\
\hline IDT $\left({ }^{\circ} \mathbf{C}\right)$ & 359.3 & 359 & 355 & 361 \\
$\mathbf{5 0 \%}\left({ }^{\circ} \mathbf{C}\right)$ & 384 & 388 & 384 & 386 \\
Inf $\left({ }^{\circ} \mathbf{C}\right)$ & 391 & 394 & 389 & 392 \\
FDT $\left({ }^{\circ} \mathbf{C}\right)$ & 415 & 422 & 416 & 417 \\
Residues (\%) & 6.24 & 7.76 & 9.1 & 9.94 \\
\hline
\end{tabular}

The thermogravimetric analysis is essential and will show the composites thermal properties over a temperature range indicating how stable the material is. Plenty of scientific articles found in the literature dealt with UPR thermal properties using TGA and showed that UPR thermal degradation is a one step process occurring between 350$420^{\circ} \mathrm{C}$ [7], a 2-step degradation process has been reported in some other studies, where the first degradation has been attributed to water molecules evaporation and therefore, it 
appeared at around $80-120^{\circ} \mathrm{C}$. Table 5 summarizes the thermal properties of the analyzed composites.

The TGA thermogram of non-reinforced UP (C1) indicated that initial degradation temperature (IDT) is $359.3^{\circ} \mathrm{C}$ and a final degradation temperature (FDT) of $415^{\circ} \mathrm{C}$. From TGA curves in Figure 2, it can be noticed that the incorporation of $10 \%$ natural fiber (neat and hybrid) had no significant effect on the IDT and the FDT, thermograms of C2, C4 and C7 respectively indicated a slight decrease of IDT by $1.84 \%$, $2.84 \%$ and $4.22 \%$ respectively, and a decreased FDT by $0.65 \%, 0.85 \%$ and $1.63 \%$, respectively.

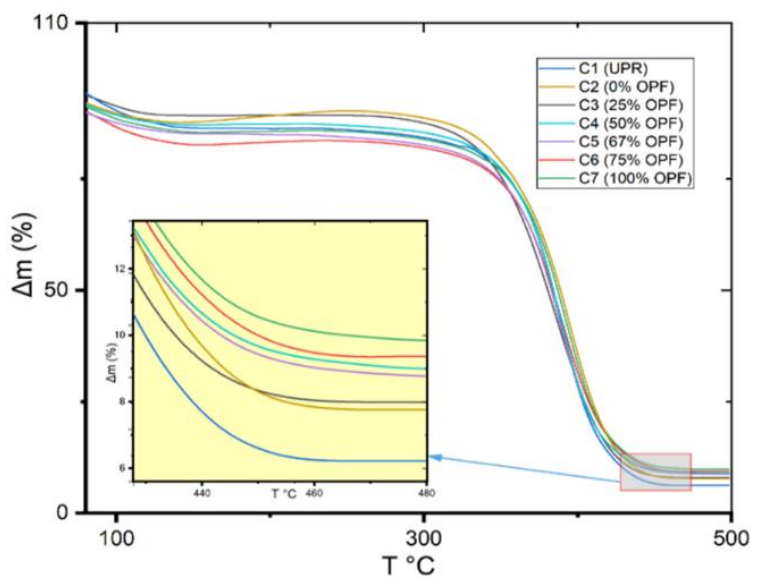

Figure 2. TG of the UPR and the prepared composites

With regard to final residue (FR) and as expected, neat UPR (C1) left less residue $(6.24 \%)$, but with incorporation of $10 \%$ DPLF in C2, the residue was slightly increased to $7.76 \%$, and keep increasing with increase of OPF proportion over DPLF one, until it reaches $9.94 \%$ in $\mathrm{C} 7$ (10\% OPF). These results were expected because of use of untreated OPF over mercerized DPLF.

The thermogravimetric analysis of the prepared composites after the incorporation of different ratios of hybrid DPLF-OPF showed a clear differentiation regarding the residues after $400^{\circ} \mathrm{C}$. According to the results found in regards to residues, the addition of OPF with different percentages gives a thermal stability to the composites which is linked to the good OP fiber dispersion in the polymeric matrix, these results are in perfect

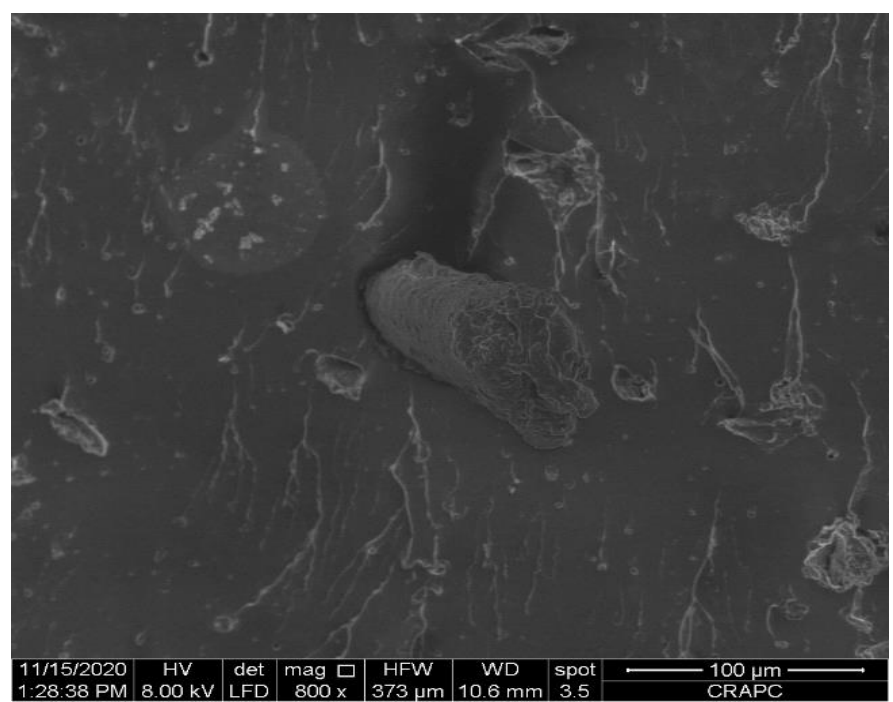

accordance with the results found in the mechanical analysis part, hence, the addition of both OPF and DPF as hybrid fillers improve the most the thermal properties.

\subsection{Water uptake}

The Figure 3 shows the water absorption (\%) of prepared composites $\mathrm{C} 1$ to $\mathrm{C} 7$, in a period exceeding 50 days.

From the Figure 3, it can be seen that the maximum water uptake of $\mathrm{C} 1$ (non-reinforced UPR) is up to $1.24 \%$, reached after 27 days immersion. As expected, adding the natural fibers to the UPR reduce significantly the composite hydrophobicity, from the water uptake graph, it is seen that $\mathrm{C} 2$ with $10 \%$ DPLF caused $79.8 \%$ increase in water uptake (up to $2.24 \%$ of total sample weight), this increase in water uptake continues with increasing OPF and decreasing DPLF until a maximum water uptake is reached in C7 (10\% OPF and $0 \%$ DPLF) where a $226.2 \%$ increase is noticed compared to the water uptake of non-filled UPR.

This is due to DPLF being surface modified, knowing that the surface modification of the fiber reduces the number of hydroxyl groups on the surface, which gives a better UPRDPLF adhesion [17], hence, a low water uptake rates were noticed with treated DPLF compared to untreated OPF.

These results are in accordance with morphological micrographs of C2 and C7 discussed previously.

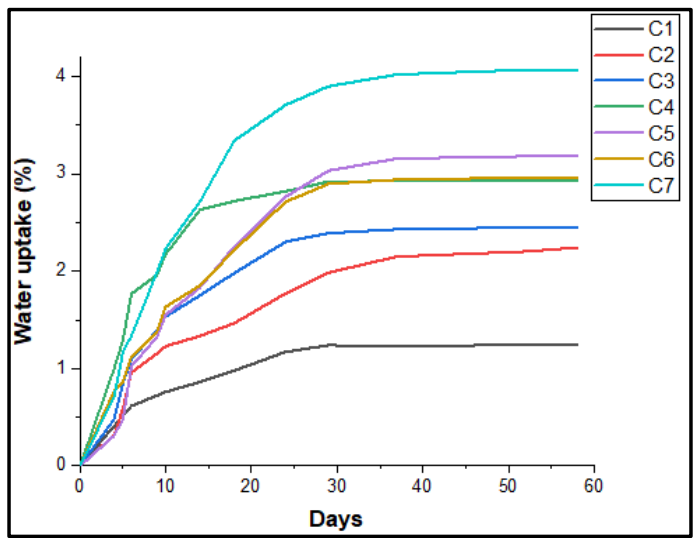

Figure 3. Water uptake of the prepared composites

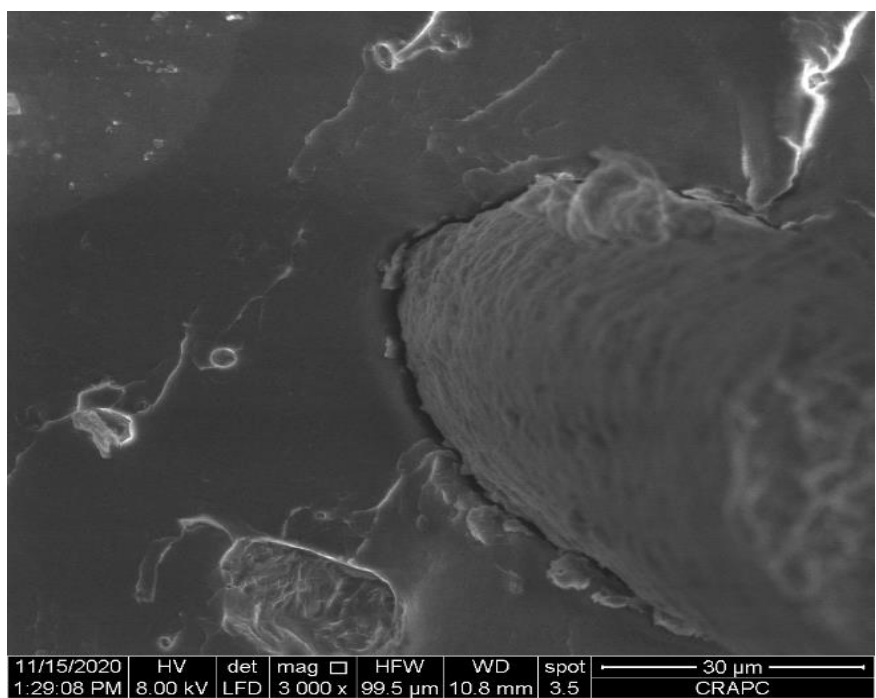

Figure 4. SEM micrographs of tensile fractured C1 composite (10\% DPLF) 

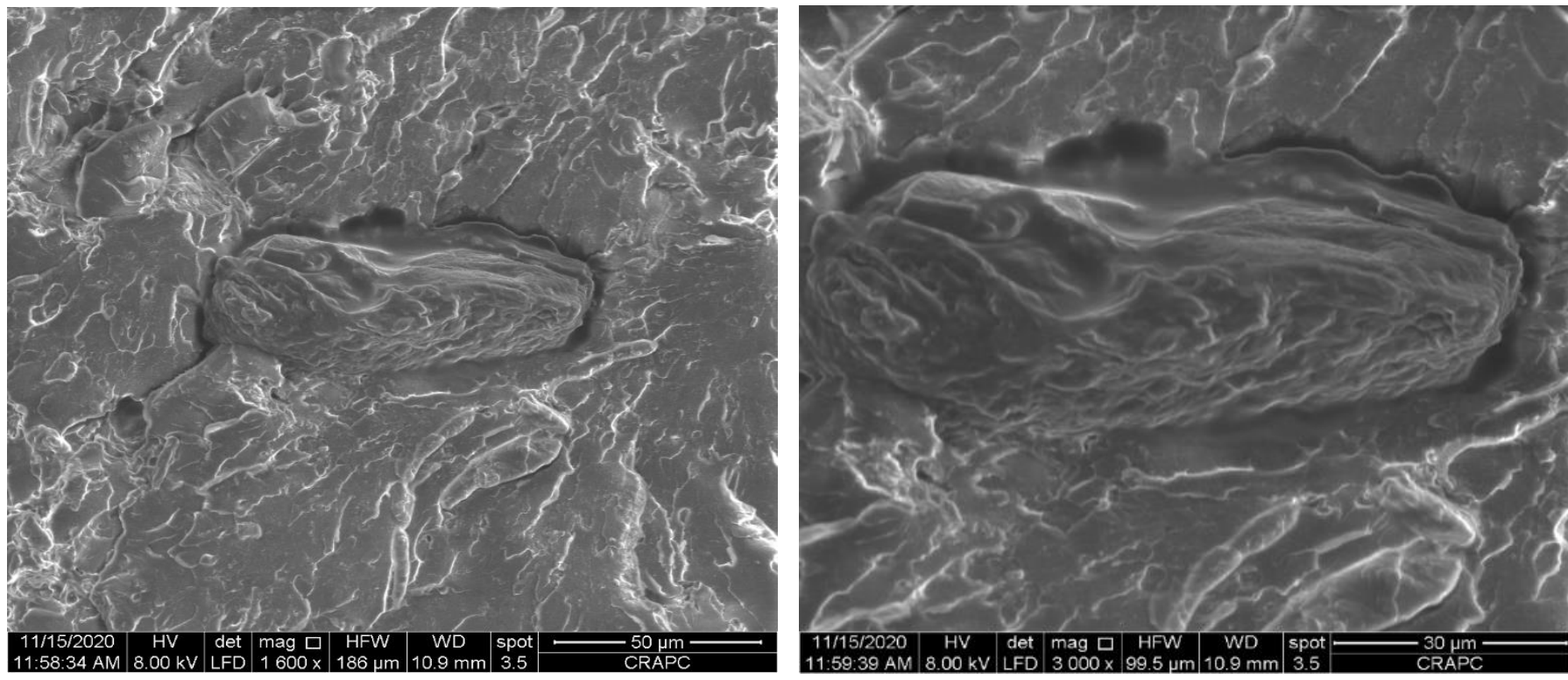

Figure 5. SEM micrographs of tensile fractured C7 composite (10\% OPF)

\section{CONCLUSION}

In this study, a hybrid composites of DPLF/OPF reinforced unsaturated polyester resin were prepared, in the aim of studying the influence of the fillers on the curing parameters of the UPR, improving the mechanical properties as well as measuring the impact of the fillers on the hydrophobicity of the UPR. The outcomes of this study are illustrated below:

(1) The optimum tensile strength $(2.2 \pm 1.9 \mathrm{MPa})$ was attributed to $10 \%$ OPF composite (C7) with $35.86 \%$ improvement compared to non-reinforced UPR. Although the composites C4, C5 and C6 with hybrid fillers did not show an optimum regarding mechanical properties, these hybrid composites showed improved mechanical properties compared to neat UPR. On this basis, it can be concluded from mechanical analysis as well as from morphological investigation that filler hybridization in UPR composite that improved mechanical properties, can be achieved using DPLF/OPF.

(2) SEM micrographs showed a better OPF-UPR adhesion in fractured specimen, with both OPF and UPR having a rough surface, which explains the improved tensile strength in OPF composites.

(3) To the best of our knowledge, this is the first study on the influence of natural fillers on the curing parameters of UPR Importantly and while DPLF was found to have no effect, the results from curing parameters analysis provide evidence that OPF affects the curing properties with the UPR tgel increased by $270 \%$. Studies of the curing parameters have shown that chemical species in the OPF acts as natural inhibitor of UPR curing reaction and delay the peak exothermic temperature by $207.14 \%$.

(4) The findings from water uptake study indicated that composites with higher OPF proportions absorbed more water, this result was expected, since in opposition to DPLF, OPF was studied without chemical surface modification.

Future research should consider the effect of OPF more carefully, for example the soak time of OPF before initiation of curing process is to be considered, since extended soak times can lead to more extracts release that contains a different amount of inhibitor components. It is a question for future research to also investigate possible surface modification of OPF in a manner that reduces the water uptake and preserve the good mechanical properties.

\section{ACKNOWLEDGMENT}

The authors wish to acknowledge the support given by ENICAB Biskra.

\section{REFERENCES}

[1] Abilash, N., Sivapragash, M. (2013). Environmental benefits of eco-friendly natural fiber reinforced polymeric composite materials. International Journal of Application or Innovation in Engineering \& Management, 2(1): 53-59.

[2] Vijayan, R., Krishnamoorthy, A. (2019). Review on natural fiber reinforced composites. Materials Today: Proceedings, 16 897-906. https://doi.org/10.1016/j.matpr.2019.05.175

[3] Athawale, A.A., Pandit, J.A. (2019). Unsaturated polyester resins, blends, interpenetrating polymer networks, composites, and nanocomposites: State of the art and new challenges. Unsaturated Polyester Resins, 142. https://doi.org/10.1016/B978-0-12-816129-6.000016

[4] Cristofaro, D., Bernardi, T. (2016). Orange Residues: from waste to resource. in XVI Giornata della Chimica dell'Emilia Romagna. University of Ferrara.

[5] Ghori, W., Saba, N., Jawaid, M., Asim, M. (2018). A review on date palm (phoenix dactylifera) fibers and its polymer composites. IOP Conference Series: Materials Science and Engineering, 368(1): 012009. https://doi.org/10.1088/1757-899x/368/1/012009

[6] Gunturu, B., Vemulapalli, C., Malkapuram, R., Konduru, N. (2020). Investigation on mechanical, thermal and water absorption properties of banana/coir reinforced polypropylene hybrid composites. Revue des Composites et des Matériaux Avancés-Journal of 
Composite and Advanced Materials, 30(3-4): 123-131. https://doi.org/10.18280/rcma.303-402

[7] Meftah, Y., Tayefi, M., Fellouh, F., Chouieur, H., Maou, S., Meghezzi, A. (2020). Influence of alkali treatment and dune sand content on the properties of date palm fiber reinforced unsaturated polyester hybrid composites. Revue des Composites et des Matériaux Avancés-Journal of Composite and Advanced Materials, 30(3-4): 161-167. https://doi.org/10.18280/rcma.303-406

[8] Lakshmi Narayana, V., Rao, L.B., Devireddy, S.B.R. (2020). Effect of fiber percentage and stacking sequence on mechanical performance of unidirectional hemp and Palmyra reinforced hybrid composites. Revue des Composites et des Matériaux Avancés-Journal of Composite and Advanced Materials, 30(3-4): 153-160. https://doi.org/10.18280/rcma.303-405

[9] Abdullah-Al-Kafi, Abedin, M.Z., Beg, M.D.H., Pickering, K.L., Khan, M.A. (2006). Study on the mechanical properties of jute/glass fiber-reinforced unsaturated polyester hybrid composites: Effect of surface modification by ultraviolet radiation. Journal of Reinforced Plastics and Composites, 25(6): 575-588. https://doi.org/10.1177\%2F0731684405056437

[10] Dahad, H.A., Hasan, S.F., Alwan, A.H. (2018). Study the effect of different percentages of natural (orange peels and date seeds) and industrial materials (carbon and silica) on the mechanical and thermal properties of polymeric reinforced composites. Al-Khwarizmi Engineering Journal, 14(4):

16-23. https://doi.org/10.22153/kej.2018.04.001

[11] Adhikari, R.K., Gowda, B.K. (2017). Exploration of mechanical properties of banana/jute hybrid polyester composite. Materials Today, 4(8): 7171-7176. https://doi.org/10.1016/j.matpr.2017.07.043

[12] Nasser, R.A., Salem, M.Z., Hiziroglu, S., Al-Mefarrej, H.A., Mohareb, A.S., Alam, M., Aref, I.M. (2016). Chemical analysis of different parts of date palm (Phoenix dactylifera L.) using ultimate, proximate and thermo-gravimetric techniques for energy production.
Energies, 9(5): 374. https://doi.org/10.3390/en9050374

[13] Ververis, C., Georghiou, K., Danielidis, D., Hatzinikolaou, D.G., Santas, P., Santas, R., Corleti, V. (2007). Cellulose, hemicelluloses, lignin and ash content of some organic materials and their suitability for use as paper pulp supplements. Bioresource technology, 98(2): 296-301. https://doi.org/10.1016/j.biortech.2006.01.007

[14] M'hiri, N., Ioannou, I., Ghoul, M., Boudhrioua, N.M. (2015). Proximate chemical composition of orange peel and variation of phenols and antioxidant activity during convective air drying. Journal of New Sciences, Agriculture and Biotechnology, 881-890.

[15] Park, J.H., Lee, M., Park, E. (2014). Antioxidant activity of orange flesh and peel extracted with various solvents. Preventive Nutrition and Food Science, 19(4): 291-298. https://dx.doi.org/10.3746\%2Fpnf.2014.19.4.291

[16] Haddad, H., Sbarski, I. (2017). Optimization of thermal and mechanical properties of unsaturated polyester resin as a binder in polymer concrete for manufacturing precision tool machine bases. J Mater Sci Eng, 6(395): 2169-0022. https://doi.org/10.4172/2169-0022.1000395

[17] Abdul Khalil, H.P.S., Ismail, H., Ahmad, M.N., Ariffin, A., Hassan, K. (2001). The effect of various anhydride modifications on mechanical properties and water absorption of oil palm empty fruit bunches reinforced polyester composites. Polymer International, 50(4): 395402. https://doi.org/10.1002/pi.642

\section{NOMENCLATURE}

$\begin{array}{ll}\text { C1 } & \text { UPR }(100 \%) \\ \text { C2 } & \text { UPR-DPLF (90 \%-10\%) } \\ \text { C3 } & \text { UPR-DPLF-OPF (90 \%-7.5 \%-2.5\%) } \\ \text { C4 } & \text { UPR-DPLF-OPF (90\%-5 \%-5 \%) } \\ \text { C5 } & \text { UPR-DPLF-OPF (90 \%-3.3 \%-6.7 \%) } \\ \text { C6 } & \text { UPR-DPLF-OPF (90\%-2.5 \%-7.5\%) } \\ \text { C7 } & \text { UPR-OPF (90\%-10\%) }\end{array}$

